\title{
AVALIAÇÃO DO POTENCIAL DE CINCO CULTIVARES DE VIDEIRAS AMERICANAS PARA SUCOS DE UVA NO SUL DE MINAS GERAIS
}

\author{
Potential evaluation of five american cultivars for grape juices in the south of Minas Gerais state
}

\author{
Giuliano Elias Pereira ${ }^{1}$, Luiz Carlos de Oliveira Lima², Murillo de Albuquerque Regina ${ }^{3}$, \\ Jean-Pierre Rosier ${ }^{4}$, Vany Ferraz ${ }^{5}$, Moisés Mourão Junior ${ }^{6}$
}

\begin{abstract}
RESUMO
Objetivou-se, no presente trabalho realizar uma caracterização dos sucos de uva de cinco cultivares de videira americana Vitis labrusca (Folha de Figo, Alwood, Concord, BRS-Rúbea e Isabel) segundo suas características visuais, olfativas e gustativas, utilizando um método descritivo por um painel de degustadores da Embrapa Uva e Vinho (EMBRAPA/CNPUV) de Bento Gonçalves e da Associação Brasileira de Enologia (ABE), constituído por doze degustadores. De acordo com os resultados, os sucos das cultivares Isabel e Folha de Figo foram superiores aos demais, segundo a análise de componentes principais (ACP), principalmente pelas variáveis limpidez, equilíbrio olfativo, intensidade e corpo gustativo, persistência olfato-gustativa e julgamento geral (notas). O suco Folha de Figo foi superior ao Isabel quanto à tonalidade, sendo o primeiro caracterizado como vermelho-violáceo. A cultivar Folha de Figo é a mais utilizada na região para a produção de suco, podendo os produtores utilizarem também a cultivar Isabel, que mostrou potencial nas condições edafo-climáticas do sul de Minas Gerais.
\end{abstract}

Termos para indexação: Vitis labrusca, cultivares, suco de uva, análise sensorial.

\section{ABSTRACT}

The present work was designed to accomplish the characterization of the different grape juices of five grapevine cultivars of Vitis labrusca (Folha de Figo, Alwood, Concord, BRS-Rúbea e Isabel) according to their visual, smell and taste characteristics utilizing a descriptive method by a panel of tasters of Embrapa Grape and Wine (EMBRAPA/CNPUV) of Bento Gonçalves, and of the Brazilian Enology Association (ABE) consisting of 12 tasters. According to the results, the juices of the cultivars Isabel and Folha de Figo were higher than the others, analyzed statistically according to the Principal Component Analysis (PCA), mainly by the visual cleanliness variables, olfatory equilibrium, gustative body and quality, olfato-gustative persistence and general judgement (scores) and the juice of Folha de Figo was higher than Isabel according to visual shade, the former being characterized as violet-red. Folha de Figo is the most used cultivar for grape juices. Isabel would be also used, with a great potential in the environmental conditions of the south of Minas Gerais estate.

Index terms: Vitis labrusca, cultivars, juice, taste analysis.

(Recebido em 26 de novembro de 2003 e aprovado em 26 de março de 2008

\section{INTRODUÇÃO}

O suco de uva é definido pela legislação brasileira como uma bebida energética não fermentada, não alcoólica, de cor, aroma e sabor característicos, sendo necessário submetê-lo a certos tratamentos para assegurar sua conservação e apresentação até o momento do consumo (Rizzon et al., 1998). A portaria 371 de 10/09/1974 do Ministério da Agricultura (Brasil, 1974) define para o Brasil três tipos de suco de uva, o suco de uva integral, onde o açúcar provém exclusivamente da uva, o suco de uva adoçado, onde parte do açúcar pode ser acrescentado na forma de sacarose e o suco de uva reconstituído, obtido a partir da dissolução do mosto concentrado.

A produção de suco de uva é economicamente importante dentro da vitivinicultura nacional. Para o estado de Minas Gerais, a utilização de somente duas cultivares para a produção de sucos, 'Folha de Figo' e 'Concord', concentra a colheita em um curto período, o que obriga as empresas a buscarem a matéria prima em outras regiões, como no Rio Grande do Sul, que se encontra a $1.500 \mathrm{Km}$ de distância, colocando em risco a qualidade e a sanidade

\footnotetext{
${ }^{1}$ Engenheiro Agrônomo, Doutor, Pesquisador - Embrapa Uva e Vinho/Semi-Árido - Br 428, Km 152 - Zona Rural - Cx. P. 23 - $56302-970$ - Petrolina, PE gpereira@cpatsa.embrapa.br

²Doutor em Ciência dos Alimentos, Professor - Departamento de Ciência dos Alimentos/DCA - Universidade Federal de Lavras/UFLA - Cx. P. 3037 37200-000 - Lavras, MG - Icolima@ufla.br

${ }^{3}$ Engenheiro Agrônomo, Doutor, Pesquisador - Empresa Agropecuária de Minas Gerais/EPAMIG - Avenida Santa Cruz, 500 - Santa Cruz - 37780 -000 Caldas, MG - murillo@epamigcaldas.gov.br

${ }^{4}$ Engenheiro Agrônomo, Doutor, Pesquisador - Empresa de Pesquisa Agropecuária e Extensão Rural de Santa Catarina/EPAGRI - Rua João Zardo, s/n Campo Experimental - Cx. P. 21 - 89560-000 - Videira, SC - rosier@formatto.com.br

${ }_{5}^{5}$ Química, Doutora, Professora - Departamento de Química - Universidade Federal de Minas Gerais/UFMG - Avenida Antõnio Carlos, 6627 - Pampulha 31270-901 - Belo Horizonte, MG - vanyferraz@ufmg.br

${ }^{6}$ Biólogo, Mestre, Pesquisador -EmbrapaAmazônia Oriental - Travessa Doutor Enéas Pinheiro, s/n-Cx.P. 48-66095-100-Belém, PA - mmourao@cpatu.embrapa.br
} 
das uvas durante o transporte. Os estudos sobre a adaptação de novas cultivares para a região são limitados, sendo necessários para poder oferecer aos produtores novas opções de sucos, tendo em vista a importância econômica dessa atividade para o sul de Minas Gerais.

A análise sensorial pode ser definida como o conjunto dos métodos e das técnicas que permitem perceber, identificar e apreciar pelos órgãos do sentido, um certo número de propriedades, ditas organolépticas dos alimentos (PEYNAUD, 1997). É uma técnica muito utilizada para avaliar as características sensoriais de alimentos e bebidas, sendo importante no meio enológico para se avaliar o produto de uma safra de uvas, de diferentes cultivares, tratamentos, bem como sua aceitação. Verificam-se grandes variações da qualidade obtida com as uvas em diferentes características de solo e clima, além do processo tecnológico adotado (BENASSI, 1997). Essa técnica requer experiência e treinamento das pessoas relacionadas a participar do julgamento, sendo necessário estarem aptas a descreverem suas percepções e formularem uma opinião (PEYNAUD, 1997).

A análise sensorial no meio enológico é o método mais completo e recomendado para se avaliar a qualidade de um suco ou vinho. Somente as análises químicas, mesmo descritivas dos constituintes, é insuficiente para tal caracterização, sendo necessária para dar suporte e complementar o resultado da análise sensorial. O primeiro sentido é o exame visual. Ele descreve os aspectos limpidez, intensidade e tonalidade do suco. O segundo é o olfativo, onde são avaliadas as características e variações de intensidade, equilíbrio, qualidade e aromas indesejáveis. $\mathrm{O}$ terceiro sentido é o gustativo, relacionado às variações de intensidade, corpo, adstringência, acidez, equilíbrio, qualidade e gostos indesejáveis (PEYNAUD, 1997). Os sentidos, particularmente o gosto e o olfato, reagem a estímulos que dependem da qualidade e quantidade das substâncias presentes no produto analisado, que entram em contato com os órgãos sensoriais. Com relação ao gosto, distinguimos quatro sabores fundamentais: doce, amargo, ácido e salgado (CHITARRA \& CHITARRA, 1990; PEYNAUD, 1997; USSEGLIO-TOMASSET, 1995).

Dentro do objetivo de analisar sensorialmente um alimento, no caso específico os sucos de uvas, devem-se minimizar as influências individuais, levando-se em conta as descrições e as características por um grupo de pessoas, que tenham conhecimento básico. Para que uma avaliação sensorial tenha consistência e que os resultados sejam corretos, fiáveis e conclusivos, é necessário que se tenha um grupo de, no mínimo, oito pessoas, minimizando, dessa forma, o efeito pessoal e subjetivo da degustação (USSEGLIO-TOMASSET, 1995).
Outra definição de importância na enologia é a degustação: degustar é provar, com atenção, um produto que queiramos apreciar a qualidade. É submetê-lo aos nossos sentidos, particularmente o gustativo e o olfativo. É tentar conhecê-lo, procurando-se expressar os seus defeitos e suas qualidades. É estudar, analisar, descrever, julgar e classificar (USSEGLIO-TOMASSET, 1995). Existem dois tipos de degustação, a técnica, realizada por profissionais ligados à área de enologia, e a hedônica, realizada por apreciadores e consumidores, sem base científica.

Objetivou-se, neste trabalho realizar uma caracterização sensorial dos sucos de uvas de cinco cultivares, julgando-os quanto aos aspectos visual, olfativo e gustativo, além de suas interações, a fim de se obter uma posição sobre o desempenho e o potencial dos sucos obtidos das diferentes cultivares, nas condições edafoclimáticas do sul de Minas Gerais. A introdução de novas cultivares na região com diferenças de ciclo produtivo pode permitir o escalonamento da colheita e diminuir os riscos de perdas qualitativas em função do tempo de espera para o processamento industrial, buscando oferecer aos produtores novas opções e buscando uma melhoria da qualidade dos sucos produzidos.

\section{MATERIALE MÉTODOS}

O presente trabalho foi realizado na Empresa de Pesquisa Agropecuária de Minas Gerais (EPAMIG), situada em Caldas-MG, a uma altitude de $1.150 \mathrm{~m}$, à $21^{\circ} 40^{\prime}$ de latitude sul e $40^{\circ}$ de longitude oeste. As cinco cultivares de Vitis labrusca estudadas, Alwood, BRS-Rúbea, Concord, Folha de Figo e Isabel, estão inseridas em uma coleção ampelográfica de cultivares, na EPAMIG. As plantas, dispostas em duas parcelas com dez plantas cada, foram implantadas em 1998, enxertadas sobre o porta-enxerto '10114' (Riparia x Rupestris), formadas em duplo cordão esporonado (sistema Royat), conduzidas em espaldeira com três fios de arame e densidade de 2.500 planta/ha $(2,0 \times 2,0$ m). O solo é arenoso-argiloso com 5,5\% de matéria orgânica. As características climáticas da região são marcadas por uma forte pluviosidade, com uma média anual de $1.187 \mathrm{~mm}$ (cujos $655 \mathrm{~mm}$ durante o verão e período de colheita), e uma temperatura média anual de $17,8^{\circ} \mathrm{C}$ (médias de $11,4^{\circ} \mathrm{C}$ para a mínima e $25,5^{\circ} \mathrm{C}$ para a máxima). A poda das plantas foi realizada em agosto de 1999, quando começaram todos os acompanhamentos agronômicos das plantas, como a fenologia das plantas e dados de produção.

O ponto de colheita das uvas foi determinado a partir do acompanhamento dos teores em açúcar e ácidos orgânicos das uvas. A partir do momento em que se observou uma estabilização da evolução da maturação, 
as uvas foram colhidas, respeitando-se os limites exigidos pela portaria do Ministério da Agricultura (BRASIL, 1974). A partir das uvas colhidas, foram feitas análises para a determinação da composição físicoquímica das mesmas.

Segundo Rizzon et al. (1998), existem vários processos para a elaboração do suco de uva. Neste trabalho, foi adotado o método de extração da cor pelo vapor d'água, sendo também utilizado pelas indústrias. Os sucos foram elaborados por método caseiro, utilizandose um extrator com capacidade para $20 \mathrm{Kg}$ de uva. Obtevese cerca de 10 a 12 litros para cada cultivar, sendo utilizada como temperatura de extração $75^{\circ} \mathrm{C}$, com o objetivo de garantir um engarrafamento antisséptico. Após o engarrafamento os sucos foram sulfitados, adicionandose para cada litro $0,1 \mathrm{~g}$ de dióxido de enxofre $\left(\mathrm{SO}_{2}\right)$, e pasteurizados, visando aumentar o período de conservação. Esse método de elaboração oferece riscos de diluição do suco pelo fato de ser obtido pelo vapor d'água, embora seja o método experimental mais utilizado (RIZZON et al., 1998).

A análise sensorial foi realizada por doze julgadores pertencentes ao Grupo de Avaliação Sensorial da Embrapa Uva e Vinho (CNPUV), de Bento GonçalvesRS e por membros da Associação Brasileira de Enologia (ABE), formado por enólogos diplomados. Foi utilizado o método descritivo de avaliação com a ajuda de uma ficha analítica de escala não estruturada e descontínua, adotada para degustação de sucos de uvas. As variáveis avaliadas foram os fatores visuais (limpidez, intensidade e coloração), olfativos (intensidade, equilíbrio, qualidade e defeitos), gustativos (intensidade, corpo, adstringência, acidez, equilíbrio e gostos indesejáveis), olfatogustativos (equilíbrio, persistência), o fator tipicidade varietal (aromas típicos) e a qualidade global notada sobre 20 pontos. A degustação dos sucos foi repetida duas vezes a fim de validar o julgamento e evitar o fator subjetivo.

A análise estatística foi realizada através de uma abordagem não paramétrica, pelo teste de Kruskal-Wallis (Programa Statistica Versão 5.0). Esse teste é um correspondente não paramétrico da análise de variância. A ordenação entre os valores centrais dos sucos foi efetuada através do teste de Duncan. O nível de significância adotado tanto no teste de efeitos quanto na ordenação dos valores centrais foi o padrão, $(\alpha=0,05)$ (CAMPOS, 1983).

\section{RESULTADOS E DISCUSSÃO}

Os resultados foram divididos em duas abordagens diferentes, univariada e multivariada.

\section{Ordenação univariada}

\section{Características agronômicas}

Com relação às características agronômicas, todas as fases do desenvolvimento vegetativo das diferentes cultivares mostraram-se significativas, com exceção do final da floração (Tabela 1). As cultivares Folha de Figo e BRS-Rúbea tiveram o início da brotação mais precoce, com 16 dias após a poda. Na média geral, as plantas iniciaram a brotação aos 17 dias após a poda, com duração de 3 dias. Para a floração, a média para o inicio foi aos 52 dias após a poda, com duração média de 9 dias. No período da maturação, o inicio médio foi aos 121 dias, com duração de 27 dias. A produtividade por planta foi variável, entre $3,47 \mathrm{Kg} /$ planta para a cultivar Alwood, que não foi estatisticamente diferente às cultivares Folha de Figo (4,03 $\mathrm{Kg} /$ planta) e Concord (4,73 Kg/planta) até $12,11 \mathrm{Kg} /$ planta para a cultivar BRS-Rúbea. A cultivar Isabel produziu em média 9,5 Kg/planta, demonstrando um vigor variável por variedade. A duração do ciclo (poda à colheita) foi variável, entre 157 dias para Folha de Figo, Alwood e Concord, 164 dias para BRS-Rúbea e 167 dias para Isabel. O peso médio de cachos também foi variável, entre 86,5 g para Folha de Figo e 213,6 g para BRS-Rúbea (Tabela 1).

$\mathrm{O}$ fator genético responde diferentemente às condições de clima e solo (LEEUWEN et al., 2004). Nas condições edafo-climáticas do sul de Minas Gerais, podese notar que as características fenológicas das diferentes cultivares foram diferentes, quanto à brotação, floração, maturação, produção e ciclo produtivo. Isso pode implicar em uma escolha de diferentes cultivares, buscando escalonar a produção e colheita, evitando, assim, possíveis sobrecargas nas indústrias da região.

\section{Características qualitativas das uvas na colheita}

No momento da colheita, foram avaliados o $\mathrm{pH}$, o ${ }^{\circ}$ Brix e a acidez total das uvas, como observa-se na Tabela 2. A cultivar Isabel apresentou o $\mathrm{pH}$ mais elevado $(3,8)$, diferindo das outras, que apresentaram valores estatisticamente semelhantes. $\mathrm{O}$ teor de ${ }^{\circ}$ Brix não teve variação entre as cinco cultivares. A acidez total variou de 1,7 \% (em gramas de ácido tartárico) para a BRS-Rúbea, 1,3 $\%$ para a Concord, 1,2\% para a Folha de Figo, 0,9\% para Alwood e 0,8 \% para Isabel. As características qualitativas das uvas foram diferentes, principalmente quanto à acidez total. O equilíbrio gustativo dos sucos de uvas é baseado principalmente na relação açúcar/acidez (RIZZON et al., 1998). A escolha de diferentes cultivares para a produção de suco pode ser favorável, buscando produzir sucos através de misturas de cultivares, em função de eventuais desequilíbrios se produzidos individualmente. 
Tabela 1 - Valores médios do ciclo de brotação, floração e maturação e produção das cultivares avaliadas, onde [I] corresponde ao início do estádio fenológico, [F] ao final do estádio, [D] duração do estádio, são expressos em dias. Valores precedidos de mesma letra não diferem significativamente a 5\%, segundo o teste de Duncan.

\begin{tabular}{|c|c|c|c|c|c|c|c|c|c|c|c|c|}
\hline & \multicolumn{5}{|c|}{ Brotação } & \multicolumn{7}{|c|}{ Floração } \\
\hline Cultivares & {$[\mathrm{I}]$} & & {$[\mathrm{F}]$} & & [D] & & {$[\mathrm{I}]$} & & {$[\mathrm{F}]$} & & [D] & \\
\hline F. de Figo & 16 & $\mathrm{~b}$ & 16 & $\mathrm{c}$ & 0 & $\mathrm{~b}$ & 50 & $\mathrm{~b}$ & 60 & $\mathrm{a}$ & 10 & $\mathrm{a}$ \\
\hline Alwood & 19 & $\mathrm{a}$ & 19 & $\mathrm{~b}$ & 0 & $\mathrm{~b}$ & 55 & $\mathrm{a}$ & 62 & $\mathrm{a}$ & 7 & $\mathrm{~b}$ \\
\hline Concord & 19 & $\mathrm{a}$ & 23 & $\mathrm{a}$ & 4 & $\mathrm{a}$ & 53 & $\mathrm{a}$ & 60 & $\mathrm{a}$ & 7 & $\mathrm{~b}$ \\
\hline BRS-Rúbea & 16 & $\mathrm{~b}$ & 22 & $\mathrm{a}$ & 6 & $\mathrm{a}$ & 52 & $a b$ & 63 & $\mathrm{a}$ & 11 & $\mathrm{a}$ \\
\hline Isabel & 14 & $\mathrm{c}$ & 20 & $\mathrm{~b}$ & 5 & $\mathrm{a}$ & 48 & $\mathrm{c}$ & 61 & $\mathrm{a}$ & 12 & $\mathrm{a}$ \\
\hline \multirow[t]{2}{*}{ Média } & 17 & & 20 & & 3 & & 52 & & 61 & & 9 & \\
\hline & \multicolumn{4}{|c|}{ Maturação } & & & \multicolumn{2}{|c|}{$\begin{array}{l}\text { Produão } \\
\text { Kg/planta }\end{array}$} & $\begin{array}{c}\text { Duração } \\
\text { ciclo (dias) }\end{array}$ & \multicolumn{3}{|c|}{$\begin{array}{c}\text { Peso } \\
\text { cachos }(\mathrm{g})\end{array}$} \\
\hline Cultivares & {$[\mathrm{I}]$} & & {$[\mathrm{F}]$} & & [D] & & & & & & & \\
\hline F. de Figo & 108 & $\mathrm{c}$ & 136 & d & 27 & $\mathrm{~b}$ & 4,03 & $\mathrm{c}$ & 157 & $\mathrm{c}$ & 86,54 & $\mathrm{c}$ \\
\hline Alwood & 109 & $\mathrm{c}$ & 140 & $\mathrm{c}$ & 31 & $\mathrm{a}$ & 3,47 & $\mathrm{c}$ & 157 & $\mathrm{c}$ & 98,68 & $\mathrm{c}$ \\
\hline Concord & 127 & $\mathrm{~b}$ & 149 & $\mathrm{~b}$ & 23 & $\mathrm{c}$ & 4,73 & $\mathrm{c}$ & 157 & $\mathrm{c}$ & 132,62 & $\mathrm{~b}$ \\
\hline BRS-Rúbea & 120 & $\mathrm{~b}$ & 145 & $\mathrm{~b}$ & 25 & $\mathrm{~b}$ & 12,11 & $\mathrm{a}$ & 164 & $\mathrm{~b}$ & 213,64 & $\mathrm{a}$ \\
\hline Isabel & 135 & $\mathrm{a}$ & 162 & $\mathrm{a}$ & 27 & $\mathrm{~b}$ & 9,50 & $\mathrm{~b}$ & 177 & $\mathrm{a}$ & 130,55 & $\mathrm{~b}$ \\
\hline Média & 121 & & 148 & & 27 & & 6,63 & & 162 & & 132,40 & \\
\hline
\end{tabular}

Tabela 2 - Características analíticas das uvas na colheita. A acidez total é expressa em \% (g/L de ácido tartárico). Valores precedidos de mesma letra não diferem significativamente a 5\%, segundo o teste de Duncan.

\begin{tabular}{cccccc}
\hline & Folha de Figo & Alwood & Concord & BRS-Rúbea & Isabel \\
\hline $\mathrm{pH}$ & $3,6 \mathrm{~b}$ & $3,5 \mathrm{~b}$ & $3,4 \mathrm{~b}$ & $3,5 \mathrm{~b}$ & $3,8 \mathrm{a}$ \\
\hline${ }^{\circ}$ Brix & $16 \mathrm{a}$ & $15 \mathrm{a}$ & $15 \mathrm{a}$ & $15 \mathrm{a}$ & $15 \mathrm{a}$ \\
\hline Acidez total & $1,2 \mathrm{~b}$ & $0,9 \mathrm{c}$ & $1,3 \mathrm{~b}$ & $1,7 \mathrm{a}$ & $0,8 \mathrm{c}$ \\
\hline
\end{tabular}

\section{Características sensoriais dos sucos de uvas}

\section{Características Visuais}

Dentro destas características, pôde-se notar variações significativas quanto à limpidez, intensidade $\mathrm{e}$ tonalidade dos diferentes sucos analisados. Os sucos das cultivares Folha de Figo e Isabel obtiveram melhor classificação quanto à limpidez em relação aos demais. $\mathrm{O}$ suco da Folha de Figo obteve melhor qualidade quanto à intensidade e à tonalidade visual em relação aos demais, sendo esse resultado explicado pelo melhor equilíbrio entre os compostos desse suco, principalmente com relação às antocianinas. Para a variável tonalidade, o suco da cultivar Concord foi insatisfatório, sendo julgado como vermelhotijolo, sendo que o ideal é o vermelho-violáceo, resultado obtido pelo suco Folha de Figo (Tabela 3).

\section{Características olfativas}

Com relação às características olfativas, observouse uma variação significativa com relação ao equilíbrio olfativo (Tabela 3). Os sucos das cultivares Isabel e Folha de Figo mostraram-se superiores aos demais, sendo que os compostos responsáveis por essa variável são ésteres voláteis, principalmente antranilato de metila para as videiras americanas (Vitis labrusca) (RIZZON et al., 1998). Notouse nos outros sucos aromas que os depreciavam, principalmente com relação às notas de evolução e oxidação.

\section{Características gustativas}

De acordo com a Tabela 3, pôde-se verificar que houve diferenças significativas quanto ao corpo $(\mathrm{p}<0,01)$, à intensidade e à qualidade gustativa dos sucos $(\mathrm{p}<0,05)$, tendo os sucos de Folha de Figo e Isabel recebido os 
melhores conceitos em relação aos demais. Essas variáveis avaliadas estão relacionadas principalmente à concentração em taninos presentes nos sucos e também com relação ao equilíbrio entre sólidos solúveis totais e acidez, essa expressa em termos dos ácidos tartárico, málico e cítrico no caso da uva (PEYNAUD, 1997). O equilíbrio entre o doce e o ácido é fundamental para a qualidade do suco, sendo que o sabor doce reflete e colabora com a estrutura, juntamente com os taninos, enquanto que a acidez participa no frescor e conservação do produto (RIZZON et al., 1998).

\section{Características olfativo-gustativas}

Dentro destas características sensoriais, os sucos de Folha de Figo e Isabel se mostraram superiores aos demais com relação ao equilíbrio e persistência olfato-gustativa, como se observa na Tabela 3. Nesse caso foi julgada a correlação entre as variáveis olfativas e gustativas.

\section{Características varietais e julgamento global}

Pôde-se comprovar a superioridade dos sucos Isabel e Folha de Figo em relação aos demais quanto ao julgamento global (notas), como pode ser observado na Tabela 3. Esses dois sucos receberam notas acima da média pelos julgadores, principalmente devido ao equilíbrio de suas características sensoriais avaliadas. Em relação à tipicidade varietal, foi observada variação significativa entre os cinco sucos, sendo que Folha de Figo, BRS-Rúbea e Isabel mostraram-se mais tipicamente relacionados com o aroma foxado, característico das cultivares de videiras americanas, em relação às cultivares Alwood e Concord.

A Tabela 3 ilustra as diferentes variáveis sensoriais analisadas para cada suco de uva, de acordo com suas características visuais, olfativas, gustativas, olfatogustativas, tipicidade e nota global.

Tabela 3 - Valores médios ordenados segundo o teste de Duncan, para o conjunto de variáveis sensoriais analisadas nos cinco sucos de uvas.

\begin{tabular}{|c|c|c|c|c|c|c|}
\hline Cultivares & Limpidez & Intensidade & Tonalidade & Intensidade & Equilíbrio & Qualidade \\
\hline \multicolumn{4}{|c|}{ Visual } & \multicolumn{3}{|c|}{ Olfativa } \\
\hline F. Figo & $4,10 \mathrm{a}$ & $5,56 \mathrm{a}$ & $0,20 \mathrm{~d}$ & $3,82 \mathrm{a}$ & $3,63 \mathrm{a}$ & $3,68 \mathrm{a}$ \\
\hline Alwood & $1,99 \mathrm{~b}$ & $2,28 \mathrm{c}$ & $2,27 \mathrm{~b}$ & $3,20 \mathrm{a}$ & $2,76 \mathrm{~b}$ & $3,00 \mathrm{~b}$ \\
\hline Concord & $1,21 \mathrm{~b}$ & $1,73 \mathrm{~d}$ & $2,99 \mathrm{a}$ & $3,30 \mathrm{a}$ & $2,95 \mathrm{~b}$ & $3,11 \mathrm{~b}$ \\
\hline BRS-Rúbea & $1,99 \mathrm{~b}$ & $2,35 \mathrm{c}$ & $2,21 \mathrm{~b}$ & $3,12 \mathrm{a}$ & $3,04 \mathrm{~b}$ & $3,24 \mathrm{~b}$ \\
\hline Isabel & $3,65 \mathrm{a}$ & $4,39 \mathrm{~b}$ & $1,71 \mathrm{c}$ & $3,75 \mathrm{a}$ & $3,71 \mathrm{a}$ & $3,80 \mathrm{a}$ \\
\hline Média & 2,59 & 3,26 & 1,88 & 3,44 & 3,22 & 3,36 \\
\hline Cultivares & Aromas & Intensidade & Corpo & Adstringência & Acidez & Equilíbrio \\
\hline \multicolumn{4}{|c|}{ Indesejáveis } & \multicolumn{3}{|c|}{ Gustativa } \\
\hline F. Figo & $0,69 \mathrm{~b}$ & $3,88 \mathrm{~b}$ & $4,32 \mathrm{a}$ & $2,53 \mathrm{a}$ & $3,21 \mathrm{a}$ & $3,64 \mathrm{a}$ \\
\hline Alwood & $1,45 \mathrm{a}$ & $3,39 \mathrm{c}$ & $2,94 \mathrm{c}$ & $1,10 \mathrm{c}$ & $2,78 \mathrm{~b}$ & $3,05 \mathrm{~d}$ \\
\hline Concord & $0,74 \mathrm{~b}$ & $2,97 \mathrm{c}$ & $2,64 \mathrm{c}$ & $1,84 \mathrm{~b}$ & $3,24 \mathrm{a}$ & $2,67 \mathrm{c}$ \\
\hline BRS-Rúbea & $0,73 \mathrm{~b}$ & $2,99 \mathrm{c}$ & $2,93 \mathrm{c}$ & $2,23 \mathrm{a}$ & $3,40 \mathrm{a}$ & $3,08 \mathrm{~b}$ \\
\hline Isabel & $0,72 \mathrm{~b}$ & $4,03 \mathrm{a}$ & $3,73 \mathrm{~b}$ & $1,84 \mathrm{~b}$ & $2,73 b$ & $3,79 \mathrm{a}$ \\
\hline Média & 0,86 & 3,45 & 3,31 & 1,91 & 3,07 & 3,25 \\
\hline Cultivares & $\begin{array}{l}\text { Qualidade } \\
\text { Gustativa }\end{array}$ & $\begin{array}{c}\text { Gostos } \\
\text { Indesejáveis }\end{array}$ & $\begin{array}{c}\text { Equilíbrio } \\
\text { Olfato - } \\
\text { Gustativo }\end{array}$ & $\begin{array}{c}\text { Persistência } \\
\text { Olfato - } \\
\text { Gustativo }\end{array}$ & $\begin{array}{c}\text { Tipicidade } \\
\text { Varietal }\end{array}$ & $\begin{array}{l}\text { Julgamento } \\
\text { Nota Global }\end{array}$ \\
\hline F. Figo & $3,97 \mathrm{a}$ & $0,96 \mathrm{a}$ & $3,96 \mathrm{a}$ & $3,78 \mathrm{a}$ & $4,14 \mathrm{a}$ & $15,17 \mathrm{a}$ \\
\hline Alwood & $3,19 \mathrm{~b}$ & $1,03 \mathrm{a}$ & $3,14 \mathrm{~b}$ & $3,30 \mathrm{~b}$ & $3,21 \mathrm{~b}$ & $12,38 \mathrm{~b}$ \\
\hline Concord & $2,83 \mathrm{~b}$ & $1,04 \mathrm{a}$ & $2,74 \mathrm{c}$ & $2,73 \mathrm{c}$ & $3,22 \mathrm{~b}$ & $10,83 \mathrm{~b}$ \\
\hline BRS-Rúbea & $3,11 \mathrm{~b}$ & $0,79 \mathrm{a}$ & $3,22 \mathrm{~b}$ & $3,25 \mathrm{~b}$ & $4,23 \mathrm{a}$ & $11,58 \mathrm{~b}$ \\
\hline Isabel & $3,80 \mathrm{a}$ & $0,54 \mathrm{a}$ & $3,88 \mathrm{a}$ & $3,76 \mathrm{a}$ & $3,90 \mathrm{a}$ & $15,54 \mathrm{a}$ \\
\hline Média & 3,38 & 0,87 & 3,39 & 3,37 & 3,74 & 13,10 \\
\hline
\end{tabular}

Onde: Valores precedidos de mesma letra na vertical, não diferem significativamente ao nível de $5 \%$ ( $<<0,05)$, segundo o teste de Duncan. 


\section{Ordenação multivariada}

\section{Análise de componentes principais}

A analise estatística multivariada (KEMSLEY, 1998) foi efetuada sobre os resultados da avaliação sensorial dos cinco sucos de uvas. As medidas das variáveis da análise sensorial foram reduzidas a quatro componentes principais (CP), explicando em $67,36 \%$ da variação total dos dados. Os dois primeiros CP explicaram 52,78\% da variabilidade total. Somente os componentes principais I e IV se mostraram significativos em relação à discriminação dos diferentes sucos. O componente principal I foi significativo para as características gustativas (intensidade, equilíbrio e qualidade), visuais (limpidez e intensidade), olfativas (equilíbrio e qualidade), olfato-gustativas (equilíbrio e persistência) e julgamento/nota global. O componente principal IV apresentou diferenças significativas quanto à tonalidade visual.

Pela Figura 1, que ilustra as distâncias euclidianas dos diferentes sucos, observou-se a separação dos sucos Isabel e Folha de Figo, que forram agrupados, em relação aos demais de acordo com a CP I, expressando a superioridade dos mesmos. O CP IV separou esses dois e elegeu o suco Folha de Figo como preferencial pelos julgadores. Os sucos Alwood, Concord e BRS-Rúbea foram julgados inferiores aos demais, apresentando algumas deficiências. Quanto à análise visual, apresentaram limpidez e tonalidade deficientes. Quanto à avaliação olfativa, não apresentaram equilíbrio. Em relação às variáveis gustativas, apresentaram qualidade, intensidade e corpo pouco satisfatórios. Apresentaram equilíbrio olfato-gustativo desagradável em relação aos demais, além de receberem no julgamento global (notas), valores que os colocaram idênticos, mas inferiores aos sucos Isabel e Folha de Figo.

Zanus (1991) estudando a análise sensorial de três sucos produzidos de três cultivares, obteve como resultado no julgamento sensorial em primeiro lugar o suco da cultivar Concord, seguido de Folha de Figo e Isabel. Esse ensaio foi conduzido no estado do Rio Grande do Sul. A característica sensorial está relacionada não somente com o efeito genético da cultivar utilizada, mas depende muito das características do clima e solo atuantes no campo experimental e também da sanidade e tecnologia empregadas na extração e obtenção do suco. As características edafo-climáticas regionais influenciam a qualidade das uvas (LEEUWEN et al., 2004), sendo diferentes as condições do meio nas regiões sul e sudeste do Brasil. A idade das plantas é outro fator que pode influenciar a composição e a qualidade de uvas e sucos.
Folha de figo

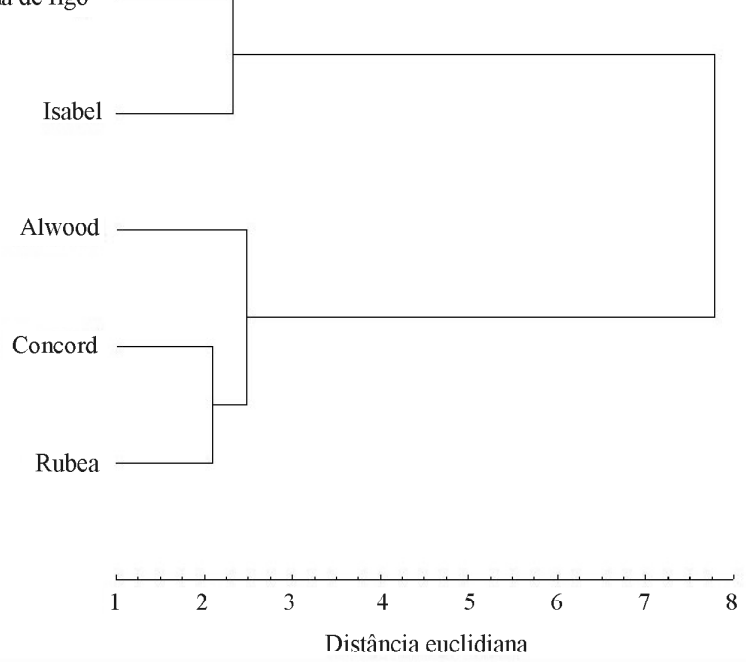

Figura 1 - Dendograma de dissimilaridade entre as cultivares de videiras.

\section{CONCLUSÕES}

No presente trabalho, cinco cultivares de videira foram avaliadas quanto ao potencial dos sucos de uvas, nas condições edafo-climáticas do sul de Minas Gerais. As cultivares tiveram diferentes respostas quanto às condições de clima e solo com relação às características fenológicas. A produção, o tamanho dos cachos, a duração do ciclo produtivo foram variáveis. Além dos fatores do meio, o fator genético pode também influenciar o desenvolvimento das plantas.

Com relação à qualidade das uvas na colheita, diferentes valores foram encontrados, principalmente quanto à acidez das uvas. Essa característica pode ser um fator a ser levado em consideração, visto que o equilíbrio e a estrutura dos sucos são baseados sobre a relação açúcar/acidez.

No que diz respeito à análise sensorial dos cinco sucos, os sucos Isabel e Folha de Figo foram eleitos superiores aos demais, de acordo com as variáveis limpidez e intensidade visual, equilíbrio e qualidade olfativa, intensidade, equilíbrio e qualidade gustativa, equilíbrio e persistência olfato-gustativo e julgamento global. O suco da cultivar Folha de Figo foi superior ao da Isabel na variável tonalidade, sendo escolhido como a cultivar ideal para a elaboração do suco de uva comercial, nas condições do sul de Minas Gerais. Essa cultivar é atualmente a mais utilizada para esse fim no sul de Minas Gerais. Os sucos das cultivares BRS-Rúbea, Alwood e Concord apresentaram algumas deficiências quando comparados aos sucos Isabel e Folha de Figo, em relação às 
características visuais (limpidez e tonalidade), olfativas (falta de equilíbrio) e gustativas (qualidade, intensidade e corpo insatisfatórios). Conclui-se que a cultivar Isabel poderia ser utilizada como opção aos produtores para a elaboração de suco de uva, buscando escalonar a colheita e o processamento, visto que apresenta ciclo produtivo diferente da cultivar Folha de Figo, além de buscar melhorar ainda mais a qualidade dos sucos. Mas não se devem descartar as outras cultivares, sendo necessário dar continuidade aos trabalhos de caracterização de cultivares para a confirmação dos resultados obtidos, pois as plantas eram jovens, com apenas dois anos.

\section{REFERÊNCIAS BIBLIOGRÁFICAS}

BENASSI, M. de T. Metodologia analítica para avaliação de parâmetros físico-químicos e sensoriais de qualidade em vinhos Riesling itálico nacionais. 1997. 150 f. Dissertação (Mestrado) - Universidade Estadual de Campinas, Campinas, 1997.

BRASIL. Ministério da Agricultura. Secretaria Nacional de Defesa Agropecuária. Secretaria de Inspeção de Produtos Vegetais. Complementação de padrões de identidade e qualidade para suco, refresco e refrigerante de uva. Brasília, DF, 1974. 29 p.
CAMPOS, H. de. Estatística experimental não paramétrica. 4. ed. Piracicaba: ESALQ, 1983. 349 p.

CHITARRA, M. I. F.; CHITARRA, A. B. Pós-colheita de frutos e hortaliças: fisiologia e manuseio. Lavras: ESAL/ FAEPE, 1990. 320 p.

KEMSLEY, E. K. Discriminant analysis of spectroscopic data. Chichester: Wiley, 1998. 179 p.

LEEUWEN, C. van; FRIANT, P.; CHONÉ, X.; TREGOAT, O.; KOUNDOURAS, S.; DUBOURDIEU, D. The influence of climate, soil and cultivar on terroir. American Journal of Enology and Viticulture, v. 55, p. 207-217, 2004.

PEYNAUD, E. Connaissance et travail du vin. 2. ed. Paris: Dunod, 1997. $341 \mathrm{p}$.

RIZZON, L. A.; MANFROI, V.; MENEGUZO, J. Elaboração de suco de uva na propriedade vitícola. Bento Gonçalves: Embrapa-CNPUV, 1998. 24 p. (Documentos, 21).

USSEGLIO-TOMASSET, L. Chimie oenologique. 2. ed. [S.1.]: Lavoisier Techniqe et Documentation, 1995. 387 p.

ZANUS, M. C.Efeito da maturação sobre a composição do mosto e qualidade do suco de uva. 1991. 177 f.Dissertação(Mestrado)Universidade Federal do Rio Grande do Sul, Porto Alegre, 1991. 